\title{
The Incorporation of NMDA Receptors with a Distinct Subunit Composition at Nascent Hippocampal Synapses In Vitro
}

\author{
Kenneth R. Tovar and Gary L. Westbrook \\ Vollum Institute, Oregon Health Sciences University, Portland, Oregon 97201-3098
}

Activity-dependent synaptic rearrangements during CNS development require NMDA receptor activation. The control of NMDA receptor function by developmentally regulated subunit expression has been proposed as one mechanism for this receptor dependence. We examined the phenotype of synaptic and extrasynaptic NMDA receptors during the development of synaptic load using the NMDA receptor $2 \mathrm{~B}$ (NR2B)-selective antagonist ifenprodil. In cultured rat hippocampal neurons when relatively few synapses had formed, the ifenprodil block of EPSCs was less than whole-cell currents, the latter of which included both synaptic and extrasynaptic receptors. At the same developmental stage, we found that extrasynaptic receptors outnumbered synaptic receptors by $3: 1$; thus whole-cell currents were dominated by the extrasynaptic population. We used the macroscopic kinetics of ifenprodil block to distinguish between the receptor populations. The ifenprodil kinetics of whole-cell currents from neurons before and during the devel-

The NMDA receptor is implicated in developmentally associated synaptic rearrangements in the vertebrate CNS. Native NMDA receptors are assembled from NMDA receptor 1 (NR1) and NR2 subunits ( $\zeta$ and $\epsilon$ in mouse; Kutsuwada et al., 1992). The expression pattern of these subunits changes during development (Monyer et al., 1994; Sheng et al., 1994), suggesting that NMDA receptors composed of particular subunit combinations may govern the time course of the critical period during cortical development (Sheetz and Constantine-Paton, 1994). In the hippocampus, mRNA for NR1 and NR2B is predominant at times when synapses are forming, whereas mRNA for NR2A is low and then increases to plateau levels later in development (McDonald and Johnston, 1990; Monyer et al., 1994). NMDA receptor-mediated synaptic responses are not present in hippocampal slices from neonatal NR2B ${ }^{-1-}$ mice (Kutsuwada et al., 1996), implying that NR2B is required for channel formation or synaptic localization of functional NMDA receptors. Consistent with this expression pattern, mice lacking NR1 or NR2B die soon after birth (Forrest et al., 1994; Kutsuwada et al., 1996).

\footnotetext{
Received Jan. 5, 1999; revised March 5, 1999; accepted March 9, 1999.

This work was supported by National Institutes of Health Grant MH11204 and the Scottish Rite Schizophrenia Research Program, Northern Masonic Jurisdiction, USA (K.R.T.) and National Institutes of Health Grant MH46613 (G.L.W.). We thank Dr. Johannes J. Krupp for preparation and transfection of the HEK293 cells, Dr. Krupp, Dr. Pascale Chavis, and Christopher G. Thomas for useful comments on this manuscript, Drs. Jim Boulter, Bryce Vissel, Stephen Heinemann, and Shigetada Nakanishi for NMDA receptor subunit clones, and Jeff Volk for the preparation of the hippocampal cell cultures.

Correspondence should be addressed to Gary L. Westbrook, Vollum Institute, L474, Oregon Health Sciences University, 3181 SW Sam Jackson Park Road, Portland, OR 97201-3098.

Copyright (C) 1999 Society for Neuroscience $\quad 0270-6474 / 99 / 194180-09 \$ 05.00 / 0$
}

opment of synaptic load was comparable with that of wholecell currents in HEK293 cells transfected with NR1 and NR2B CDNA, indicating that extrasynaptic receptors are largely NR1/ NR2B heteromers. In contrast, synaptic receptors included both a highly ifenprodil-sensitive (NR1/NR2B) component as well as a second population with lower ifenprodil sensitivity; the reduced ifenprodil block of EPSCs was attributable to synaptic receptors with lower ifenprodil sensitivity rather than to the appearance of ifenprodil-insensitive (NR1/NR2A) receptors. Our data indicate that the synaptic NMDA receptor complement changes quickly after synapse formation. We suggest that synapses containing predominately NR1/NR2B heteromers represent "immature" sites, whereas mature sites express NMDA receptors with a distinct, presumably triheteromeric, subunit composition.

Key words: hippocampus; ifenprodil; NMDA receptors; patch clamp; synapse formation; synaptic load

The expression pattern of NMDA receptor subunits could influence the development, maintenance, and stabilization of synapses by several potential mechanisms. In heterologous expression systems (Monyer et al., 1994; Krupp et al., 1998), NMDA receptor properties are dependent on subunit composition (for review, see McBain and Mayer, 1994). Likewise, changes in subunit composition may account for the acceleration of the decay of NMDA receptor-mediated EPSCs seen during development (Carmingnoto and Vicini, 1992; Hestrin 1992). Receptor regulation by intracellular signaling cascades may also be subunitspecific. For example, the nonreceptor tyrosine kinases src and fyn differentially regulate receptors containing NR2A or NR2B subunits (Kohr and Seeburg, 1996). Alternatively, NMDA receptors may play a structural role by specific interactions of their intracellular C-terminal domains with postsynaptic density (PSD) proteins and subsynaptic signaling machinery (Sheng and Wyszynski, 1997; Wyszynski et al., 1997; Ziff, 1997). Such a structural role might explain the observation that mice lacking the long intracellular C-terminal domain of NR2A or NR2B show the same phenotype as the respective targeted deletions (Sprengel et al., 1998).

Studies of recombinant NMDA receptors have provided pharmacological reagents that can distinguish between receptors containing different NR2 subunits. One of the most extensively studied of these is the noncompetitive antagonist ifenprodil. Xenopus oocytes expressing NR1/NR2B diheteromers are 400-fold more sensitive to ifenprodil than NR1/NR2A diheteromers (Williams, 1993). We took advantage of this selectivity and the kinetics of ifenprodil block to examine the role of NR2B-containing receptors during the period of synapse formation. NMDA recep- 
tor EPSCs and whole-cell currents were recorded in rat hippocampal neurons that formed autapses in single-neuron microcultures. Our results indicated that highly ifenprodil-sensitive NR1/NR2B diheteromers constitute the initial extrasynaptic population, whereas a second population of less ifenprodil-sensitive receptors are incorporated quickly after synapse formation.

\section{MATERIALS AND METHODS}

Neuronal cell culture. Microisland cultures were prepared as previously described (Bekkers and Stevens, 1991). Glass coverslips (31 mm; Biophysica, Baltimore, MD) were placed in $35 \mathrm{~mm}$ culture dishes (Nunc, Roskilde, Denmark), coated with $0.15 \%$ agarose, and allowed to dry. Using an atomizer, a solution of poly-D-lysine $(0.1875 \mathrm{mg} / \mathrm{ml}$ in $17 \mathrm{~mm}$ acetic acid; Sigma, St. Louis, MO) and collagen $(0.05 \mathrm{mg} / \mathrm{ml}$; Collagen Corp., Redwood City, CA) was sprayed on the agarose background to yield microdots of $100-1000 \mu \mathrm{m}$. After growth of glial feeder layers on the microdots, the CA1 region of hippocampi from postnatal day $0-1$ rats were removed, enzymatically (papain; Collaborative Research, Bedford, MA) and mechanically dissociated, and plated. Cultures were treated on day 1 with $0.2 \mathrm{mg} / \mathrm{ml} 5^{\prime}$-fluoro-2-deoxyuridine and $0.5 \mathrm{mg} / \mathrm{ml}$ uridine (FUDR; Sigma) to reduce glial proliferation, and then media were exchanged weekly.

Expression of recombinant NMDA receptors. HEK293 cells were transfected 6-12 hr after plating on $31 \mathrm{~mm}$ coverslips. NR1-1a, NR2x, and lymphocyte CD4 receptor cDNAs were transfected in a 4:4:1 ratio using the calcium phosphate method (Chen and Okayama, 1987). In cases in which two different NR2 subunits were transfected, the total amount of NR2 subunit $(1 \mu \mathrm{g})$ was kept constant (i.e., for 1:100 NR2A:NR2B, 0.01 $\mu \mathrm{g}$ of NR2A and $0.99 \mu \mathrm{g}$ of NR2B were transfected). The transfection was ended after $8-16 \mathrm{hr}$ by replacing the solution with fresh media (DMEM plus $10 \%$ fetal calf serum, $1 \%$ glutamine, $1 \%$ penicillinstreptomycin, and FUDR). Kynurenic acid (3 mM; Sigma) and D,L-AP5 (1 mM; Tocris, Ballwin, MO) were added to prevent glutamate-induced excitotoxicity (Cik et al., 1993). Transfected cells were identified using CD4 receptor antibody-coated beads (Dynabeads, M-450 CD4; Dynal, Oslo, Norway). Before recording, $1 \mu \mathrm{l}$ of Dynabead suspension was added to HEK 293 cells in $1 \mathrm{ml}$ of media and gently rocked for $15-30 \mathrm{~min}$. NR1-1a and NR2B cDNAs were gifts from Jim Boulter and Stephen Heinemann (Salk Institute, La Jolla, CA). NR2A cDNA was a gift from Shigetada Nakanishi (Kyoto University, Kyoto, Japan). Bluescript cDNA encoding NR1-1a, NR2A, and NR2B was inserted into pcDNA1/AMP (Invitrogen, San Diego, CA; Krupp et al., 1998). Lymphocyte CD4 receptor cDNA was inserted into the JPA vector provided by John Adelman (Vollum Institute). NR1-1a, the predominantly expressed splice variant in the CNS (Laurie et al., 1995), was used throughout these experiments.

Whole-cell recording and solutions. Whole-cell voltage-clamp recordings were performed on transfected HEK293 cells 12-72 hr after the end of the transfection reaction. Recordings from neurons were performed after 1-21 d in vitro (DIV). Cells were placed in a recording chamber at room temperature and continually perfused with an extracellular solution containing (in mM): $\mathrm{NaCl}$ (168), $\mathrm{KCl}(2.4)$, HEPES (10), D-glucose (10), glycine (0.001-0.01), and $\mathrm{CaCl}_{2}$ (1.3). The solution $\mathrm{pH}$ and osmolality were adjusted to final values of 7.4 and $325 \mathrm{mmol} / \mathrm{kg}$, respectively. To reduce calcium-dependent inactivation (Legendre et al., 1993), 0.2 $\mathrm{mm}$ external calcium was routinely used in agonist-containing solutions. For experiments requiring whole-cell drug applications, the intracellular solution contained (in $\mathrm{mM}$ ): Cs-methanosulfonate (125), CsCl (15), HEPES (10), $\mathrm{Cs}_{4}$-BAPTA (5), $\mathrm{Na}_{2}$-ATP (2), and $\mathrm{MgCl}_{2}$ (3). Intracellular solution for synaptic recordings contained (in $\mathrm{mM}$ ): K-gluconate (150), $\mathrm{CaCl}_{2}$ (6.23), $\mathrm{MgCl}_{2}$ (2), EGTA (10), HEPES (10), $\mathrm{NA}_{2} \mathrm{ATP}$ (2), and $\mathrm{Na}_{3} \mathrm{GTP}(0.2)$. The $\mathrm{pH}$ of intracellular solutions was adjusted to 7.4 with $\mathrm{CsOH}$ or $\mathrm{KOH}$, and osmolality was adjusted to $315 \mathrm{mmol} / \mathrm{kg}$. The $\mathrm{pCa}$ of this solution was calculated to be 7.0. Recording electrodes were pulled from borosilicate glass (TW150F-6; World Precision Instruments, Sarasota, FL) and had resistances between 1.5 and $5 \mathrm{M} \Omega$.

For drug application experiments, the membrane voltage was usually held at $-60 \mathrm{mV}$ and at -60 to $-80 \mathrm{mV}$ for synaptic recordings. Series resistance was always compensated $(70-90 \%)$. Cell input resistances ranged from 400 to $1200 \mathrm{M} \Omega$ for HEK293 cells and from 200 to $700 \mathrm{M} \Omega$ for neurons. Autaptic EPSCs were evoked by $0.5-2 \mathrm{msec}$ depolarizations to $0-20 \mathrm{mV}$. The depolarization resulted in an unclamped action potential followed by an autaptic EPSC. Data were collected using an Axopatch $1 \mathrm{C}$ and pClamp 5 software (Axon Instruments, Foster City, CA) acquired at a rate of $5 \mathrm{kHz}$ and filtered at $0.05-2.5 \mathrm{kHz}$ (eight-pole Bessel; Frequency Devices, Haverhill, MA).

NMDA (1 mM; Tocris), glutamate (1 mM; Sigma), and ifenprodil (1-10 $\mu \mathrm{M}$; Dr. B. Scanton, Synthelabo) were dissolved in extracellular solution. Some aliquots of ifenprodil were solubilized in ethanol; final ethanol concentration was $0.025 \%(\mathrm{v} / \mathrm{v})$. This concentration had no effect of whole-cell NMDA currents (data not shown). Drug applications were done using quartz flow pipes positioned $50-150 \mu \mathrm{m}$ from the cell. Each flow pipe was controlled by a solenoid valve that, in turn, was controlled by an external timer (Winston Instruments, Palo Alto, CA). Flow pipe translations were made by an attached piezoelectric bimorph driven by a stimulus isolation unit (Winston Instruments). Neurons were equilibrated in $3 \mu \mathrm{M}$ ifenprodil before and during agonist applications $(1 \mathrm{mM}$ glutamate, $100 \mathrm{msec}$ duration). For synaptic recordings, neurons were equilibrated in $3 \mu \mathrm{M}$ ifenprodil. For whole-cell experiments $300 \mathrm{~nm}$ tetrodotoxin (TTX; Sigma) and the AMPA receptor antagonist 6-cyano7-nitroquinoxaline-2,3-dione (CNQX, $5 \mu \mathrm{M}$; Tocris) were added to the extracellular solution. TTX was omitted from synaptic experiments.

Data analysis. All data were analyzed using Axograph software (Axon Instruments). Unless otherwise specified, currents from equilibrium drug application experiments were measured using a 500-1000 msec window after currents had reached steady-state amplitude. For NMDA receptormediated EPSCs, currents were measured using a 5-10 msec window centered at the peak of the EPSC. Measurements were performed on 5-10 consecutive EPSCs in the absence and presence of ifenprodil. Statistics were done using unpaired two-tailed $t$ tests or ANOVA, and significance was set at $p<0.05$. Data are reported as means $\pm \mathrm{SE}$.

\section{RESULTS}

\section{NMDA receptor-mediated EPSCs are less sensitive to} ifenprodil than whole-cell NMDA currents

We used whole-cell voltage-clamp recording to compare the sensitivity of synaptic and whole-cell NMDA currents with the subunit-specific antagonist ifenprodil. Using microisland cultures, functional synaptic contacts were detected 4-5 d after plating, as judged by the presence of spontaneous and evoked EPSCs. Neurons continued to form synapses for 2-3 weeks in vitro, as judged by the increase in EPSC amplitude and by the increase in the number of GluR1-like immunoreactive puncta (data not shown). At 5-7 DIV, ifenprodil $(3 \mu \mathrm{M})$ reversibly reduced the slow NMDA receptor-mediated component of the EPSC (Fig. 1A). This concentration of ifenprodil provides a maximal and selective block of NR1/NR2B diheteromeric receptors in heterologous expression systems (Williams, 1993; see below). However, the inhibition of EPSCs was quite variable, ranging from 15 to $50 \%$ of control, as shown for two different neurons in Figure $1 A$. The average inhibition $\left(\mathrm{I}_{\text {ifen }}\right)$ was $30.2 \pm 2.2 \%$ of control $(n=22)$. Ifenprodil had no effect on the fast AMPA receptor-mediated component $(94.1 \pm 2.3 \%$ of control; $n=3$; Fig. $1 B)$. Additionally, ifenprodil did not alter the paired pulse ratio $\left(\mathrm{P}_{2} / \mathrm{P}_{1}: 1.38 \pm 0.16\right.$ for control and $1.25 \pm 0.13$ for ifenprodil; $n=4 ; 50 \mathrm{msec}$ interstimulus interval), indicating that ifenprodil reduced NMDA receptor-mediated EPSCs by direct block of NMDA receptors rather than by a reduction of transmitter release.

For comparison, we measured the extent of ifenprodil block (3 $\mu \mathrm{M})$ in a pure population of NR1/NR2B receptors by transfecting HEK293 cells with NR1 and NR2B cDNA. As expected, ifenprodil reduced steady-state NMDA-evoked (1 mM, $20 \mathrm{sec})$ currents to $17.5 \pm 2.2 \%$ of control $(n=14$; Fig. $1 C, D)$. Before synapse formation (1-3 DIV) and after synapse formation has begun (5-7 DIV), $\mathrm{I}_{\text {ifen }}$ from whole-cell currents in neurons was not significantly different from $\mathrm{I}_{\text {ifen }}$ in recombinant receptors (11.6 $\pm 0.9 \% ; n=10$; and $21.2 \pm 2.1 \% ; n=17$, respectively; Fig. $1 C, D)$. Nonequilibrium agonist applications (1 mm glutamate, 100 $\mathrm{msec}$ ) in the continuous presence of $3 \mu \mathrm{M}$ ifenprodil resulted in a similar extent of block; $\mathrm{I}_{\text {ifen }}$ was $15.1 \pm 1.0 \%(n=9)$ of control (data not shown). The extent of block of whole-cell currents in 
A

Figure 1. Ifenprodil blocks NMDA EPSCs and whole-cell currents. $A$, NMDA EPSCs (in $5 \mu \mathrm{M}$ CNQX) from neurons at 5 (left) and $7 \mathrm{DIV}$, in control solution or with $3 \mu \mathrm{M}$ ifenprodil (ifen), plotted on the same time scale, showing the heterogeneity of ifenprodil antagonism. $B$, EPSC showing both AMPA (fast) and NMDA (slow) components of the EPSC. The fast component is unaffected by 3 $\mu \mathrm{M}$ ifenprodil. $C$, Ifenprodil block of whole-cell currents in neurons and HEK293 cells transfected with NR1-1a and NR2B is similar. In $1 \mathrm{~mm}$ NMDA, applications of $3 \mu \mathrm{M}$ ifenprodil were made to neurons (left) or transfected cells (right) once the control currents reached steady state. Currents are plotted on the same time scale. Bars above the currents represent NMDA (black) and ifenprodil (gray) applications. D, Scatterplot of ifenprodil block of EPSCs and whole-cell currents from neurons at $\leq 7$ DIV plotted with whole-cell data from HEK293 cells for comparison. Solid bars represent the group mean.

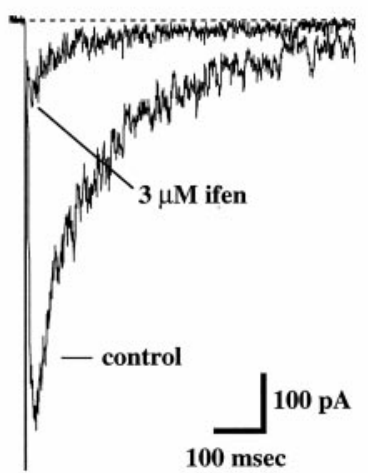

B

C

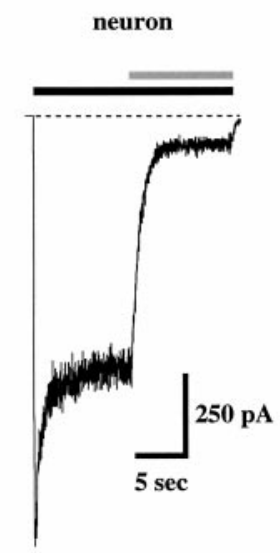

hippocampal neurons at 1-7 DIV is consistent with these currents resulting primarily from NR1/NR2B receptors. In neurons from 5-7 DIV, EPSCs were significantly less sensitive to block by ifenprodil than whole-cell currents. The difference in the ifenprodil sensitivity between synaptic and whole-cell NMDA receptors implies that the synaptic receptor complement includes NMDA receptors that are less sensitive or insensitive to ifenprodil.

\section{Synaptic and extrasynaptic NMDA receptors are differentially sensitive to ifenprodil}

Once synapses have formed, whole-cell currents reflect openings of synaptic as well as extrasynaptic NMDA receptors. Differences in subunit composition between these two receptor populations could explain the discrepancy in ifenprodil sensitivity if wholecell currents predominantly reflect the gating of extrasynaptic receptors. We took advantage of the single-axon input of microisland cultures to directly compare the ifenprodil sensitivity of the EPSC (synaptic) and whole-cell (synaptic plus extrasynaptic) current on the same neuron. As shown in Figure $2 A$, there was not an obvious correlation between ifenprodil block of EPSCs and whole-cell currents on a given neuron, but the peak whole-cell current was $55.6 \pm 17.7$ times larger than the EPSC in the same cell (Fig. $2 B ; n=7$ ). If all the receptors were synaptic, the EPSC would be expected to be fivefold smaller than the whole-cell current, assuming that the weighted average probability of transmitter release $\left(P_{\mathrm{r}}\right)$ at these terminals is $\sim 0.2$ (Rosenmund et al., 1993). However, the corrected amplitude of EPSCs is still an
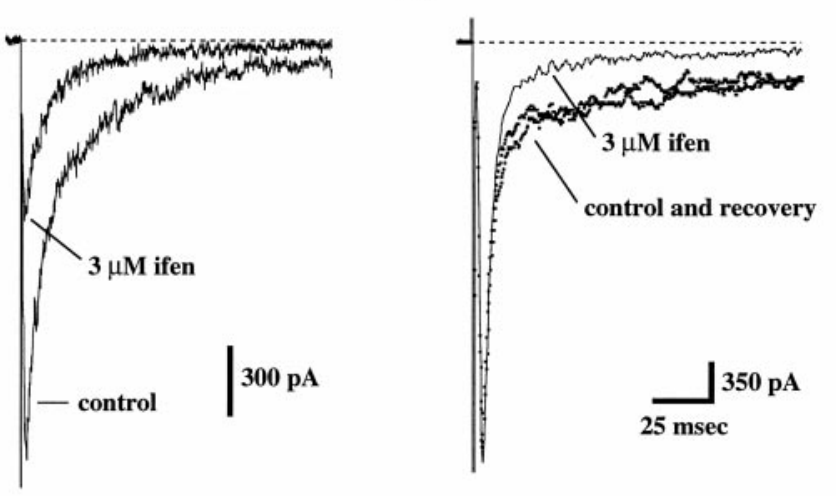

D
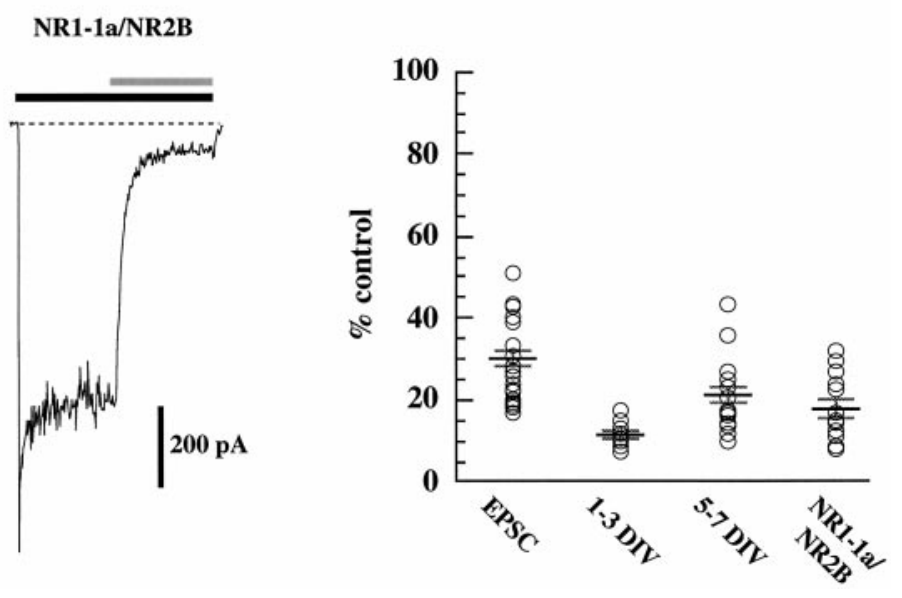

order of magnitude less than the whole-cell current, indicating that most of the functional NMDA receptors are extrasynaptic at this early stage of development.

To determine the ratio of extrasynaptic to synaptic receptors, we measured the peak current in response to $1 \mathrm{~mm}$ NMDA before and after irreversibly blocking the EPSC (in excess of 90\%) with the use-dependent antagonist MK-801 (Huettner and Bean, 1988). Using this protocol (Fig. 2C), the contribution of synaptic receptors was eliminated from the whole-cell response. In four cells, the whole-cell current remaining after block of the EPSC was $74.5 \pm 2.1 \%$ of control, indicating that extrasynaptic receptors outnumbered synaptic receptors by $3: 1$ when synaptic load is relatively low. These data indicate that the small fraction of synaptic receptors at this developmental stage has little impact on the ifenprodil sensitivity of the whole-cell current.

\section{Macroscopic kinetics of ifenprodil block}

The similar degree of block of neuronal whole-cell currents and currents from NR1/NR2B recombinant receptors suggests that extrasynaptic receptors are NR1/NR2B diheteromers. However, the pharmacological similarity does not exclude other possibilities, such as multiple NMDA receptor types within the extrasynaptic population. A comparison of the macroscopic kinetic characteristics of ifenprodil block provides a more sensitive test of this hypothesis. Figure $3 A$ shows the onset of ifenprodil block during a steady-state application of NMDA. The onset of block accelerated with the ifenprodil concentration and reached a similar 


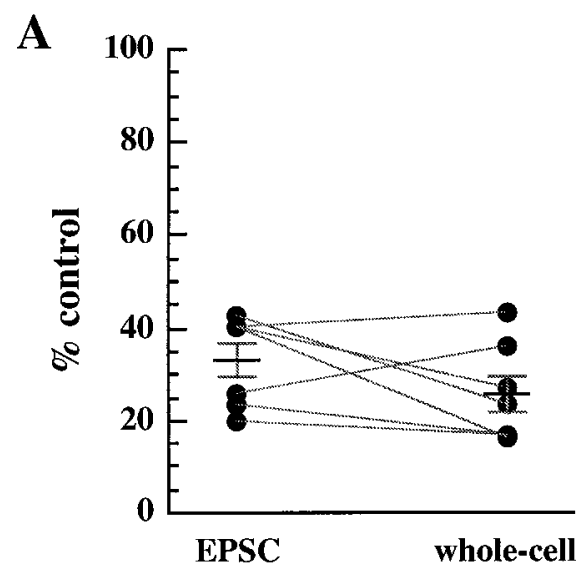

C
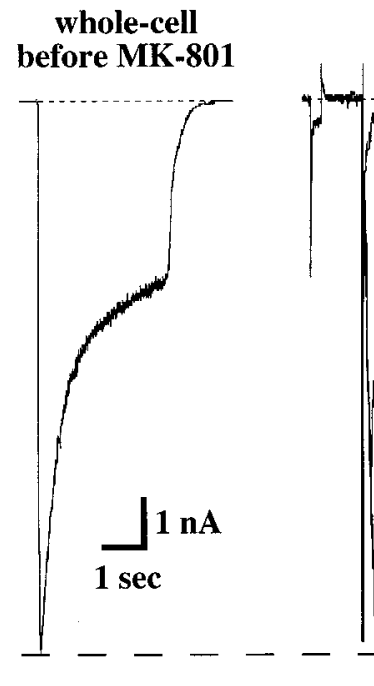

EPSC (+/- MK-801)

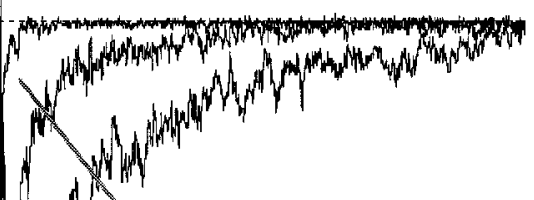

control
B

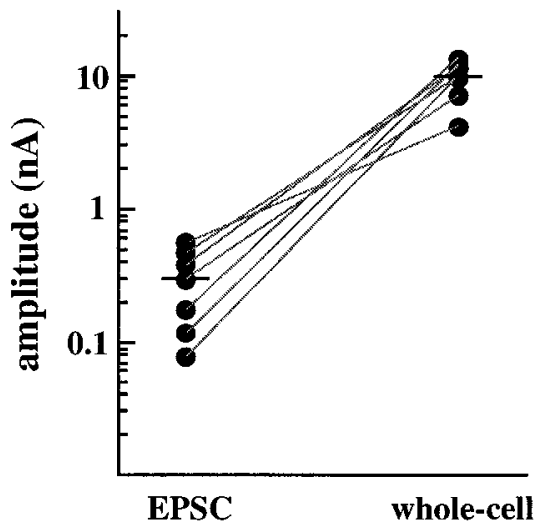

whole-cell after MK-801

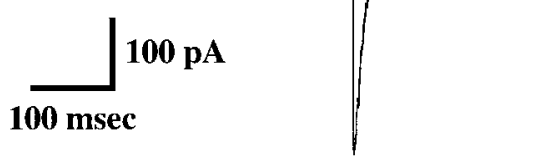

Figure 2. Extrasynaptic NMDA receptors outnumber synaptic receptors by $3: 1$ in $\leq 7$ DIV neurons. $A$, Ifenprodil sensitivity of EPSCs and whole-cell currents measured in the same neurons. Gray lines indicate the corresponding paired currents from individual neurons. $B$, Scatterplot comparison of peak EPSC and whole-cell current amplitudes from the cells in $A$. In doing a pair-wise comparison, the mean fold difference between EPSC and whole-cell current amplitudes was $55.6 \pm$ 17.7. $C$, Experimental approach used to eliminate synaptic receptors from the whole-cell current. The first current is the whole-cell response to 1 mM NMDA before any experimental manipulation. The next currents show NMDA EPSCs in control and in $5 \mu \mathrm{M}$ MK-801 [1st and 60th stimuli (stim) shown]. By the 60 th stimulus, $>95 \%$ of the EPSC has been blocked. Once EPSCs were blocked, another whole-cell application of $1 \mathrm{mM}$ NMDA was made, as shown in the final current. The difference between the peak in the first current and the last current reflects the proportion of NMDA receptors at synapses. EPSCs were stimulated at $0.1 \mathrm{~Hz}$. maximum block in both native receptors and in NR1/NR2B diheteromers. In neurons, the onset of block in 1,3 , or $10 \mu \mathrm{M}$ ifenprodil was fitted with a single exponential with time constants of $1.55 \pm 0.09(n=7), 1.41 \pm 0.19(n=18)$, and $0.32 \pm 0.03(n=$ 7) sec, respectively. The time constants for NR1/NR2B receptors were $2.12 \pm 0.58(n=5), 0.95 \pm 0.08(n=8)$, and $0.51 \pm 0.27$ $(n=5)$ sec, respectively (Fig. $3 A$ ). The onset of block was slightly slower in NR1/NR2B diheteromers at $1 \mu \mathrm{M}$ ifenprodil but not statistically different from neurons at higher concentrations. In some cases, a high concentration of ifenprodil $(10 \mu \mathrm{M})$ resulted in a fast relaxation in native and recombinant receptors, possibly reflecting a different mode of block, as previously observed at higher ifenprodil concentrations (Legendre and Westbrook, 1991).

To examine recovery from ifenprodil block, NMDA receptors were activated with $1 \mathrm{~mm}$ NMDA and then blocked with $3 \mu \mathrm{M}$ ifenprodil in the continuous presence of NMDA (Fig. $3 B$ ). After washout of ifenprodil, test pulses of NMDA (1 sec duration) were applied every $10 \mathrm{sec}$ to monitor recovery. The time required for recovery to $50 \%$ of the control amplitude was $47.2 \pm 5.8 \mathrm{sec}(n=$ 6 ) for neurons at $\leq 7 \mathrm{DIV}$ and $52.4 \pm 4.2 \mathrm{sec}$ for NR1/NR2B diheteromers $(n=5$; Fig. $3 C$ ). Thus the macroscopic kinetics of ifenprodil binding and unbinding are comparable in receptors from 5-7 DIV neurons and recombinant NR1/NR2B receptors, suggesting that the extrasynaptic receptor complement is composed largely, if not exclusively, of NR1/NR2B diheteromers.

\section{Differential ifenprodil sensitivity at "mature" synapses}

The expression of the NR2A subunit is low in rat brain before the seventh postnatal day and then increases to plateau levels 12-21 d after birth (Monyer et al., 1994; Sheng et al., 1994). A similar pattern also occurs in vitro (Zhong et al., 1994; Li et al., 1998). Because recombinant NR1/NR2A receptors are insensitive to 3 $\mu \mathrm{M}$ ifenprodil (Williams, 1993), we examined whether the ifenprodil sensitivity of NMDA receptor-mediated EPSCs decreased during this period. NMDA receptor-mediated EPSCs at $\geq 13$ DIV were significantly less sensitive to ifenprodil $\left(\mathrm{I}_{\text {ifen }}=43.1 \pm\right.$ $3.6 \%$ of control; $n=14$ ) compared with EPSCs at $\leq 7$ DIV (Fig. $4 A, B$, compare insets). AMPA receptor-mediated EPSCs at mature synapses were unaffected by $3 \mu \mathrm{M}$ ifenprodil $(95.6 \pm 4.5 \%$ of control currents; $n=4$ ), nor was the paired pulse ratio (data not shown). We blocked synaptic receptors from $\geq 13$ DIV neurons with MK-801 $(10 \mu \mathrm{M})$ and found that the ifenprodil sensitivity of extrasynaptic receptors $\left(\mathrm{I}_{\text {ifen }}=20.6 \pm 4.9 \% ; n=4\right.$; data not shown) was not different from the whole-cell ifenprodil sensitivity in $\leq 7$ DIV neurons. Thus the differential NMDA receptor distribution is even more pronounced at $\geq 13$ DIV than at $\leq 7$ DIV.

The deactivation of NMDA receptor-mediated EPSCs was faster at mature synapses, as described in other preparations (Carmingnoto and Vicini, 1992; Hestrin, 1992). This acceleration was attributable to a larger fast component of deactivation rather than a change in time constants ( $\leq 7 \mathrm{DIV}: \tau_{1}=252.2 \pm 21.4 \mathrm{msec}$; 
A
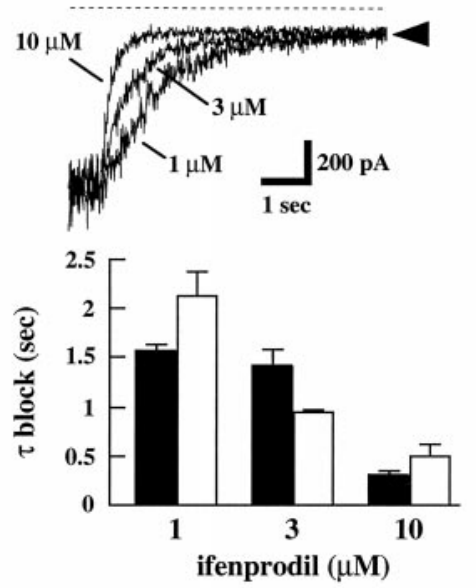

B

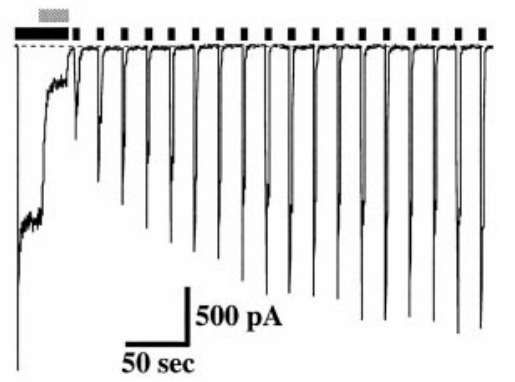

C

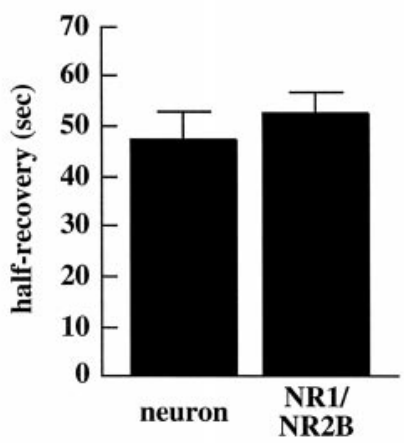

Figure 3. Macroscopic kinetic properties of NMDA receptors in $\leq 7$ DIV neurons and recombinant NR1/NR2B receptors are similar. $A$, Detail of relaxations in 1,3 , and $10 \mu \mathrm{M}$ ifenprodil, as indicated. The arrowhead indicates that the steady-state amplitude reduction is approximately the same for these three concentrations. The relaxations were fit with single exponentials, and the results are plotted below the raw data in $A$. $B$, Protocol for measuring the recovery from ifenprodil block of whole-cell currents. This example is from a neuron at 6 DIV. Bars above the current are as in Figure $1 C$. C, Bar graphs of half-recovery times using the protocol shown in $B$, showing the similarity in the recovery from block between native NMDA receptors at $\leq 7$ DIV and recombinant NR1/ $\mathrm{NR} 2 \mathrm{~B}$ receptors.

$\tau_{2}=43.7 \pm 4.5 \mathrm{msec} ; \tau_{1} / \tau_{2}$ amplitude $=1.1 \pm 0.14 ; \geq 13 \mathrm{DIV}: \tau_{1}$ $=303.3 \pm 31.4 \mathrm{msec} ; \tau_{2}=52.4 \pm 2.1 \mathrm{msec} ; \tau_{1} / \tau_{2}$ amplitude $=$ $1.7 \pm 0.26)$

The age-dependent reduction in ifenprodil sensitivity of EPSCs could result from a homogenous NMDA receptor population characterized by decreased ifenprodil sensitivity or from the presence of a pharmacologically distinct class of synaptic NMDA receptors such as ifenprodil-insensitive NR1/NR2A receptors. We used the recovery from ifenprodil block to distinguish between these possibilities. Recovery for whole-cell cur- rents was slow and monophasic (Fig. $3 B$ ); thus recovery of the ifenprodil-sensitive component of the EPSCs would be expected to be similarly slow. Likewise, if receptors with distinct ifenprodil sensitivities contribute to the EPSC, the recovery time course might be expected to be multiphasic.

As expected, for EPSCs at $\leq 7 \mathrm{DIV}$, in which ifenprodil produced a large degree of block ( $22 \%$ of control; Fig. $4 A$ ), recovery from ifenprodil block was monophasic, with a time constant $\left(\tau_{\text {slow }}\right)$ of $88.6 \pm 21.1 \mathrm{sec}(n=11$; Fig. $4 D)$. In contrast, for EPSCs showing a lower ifenprodil sensitivity at $\geq 13$ DIV $(59 \%$ of control; Fig. 4B), a rapid initial component of recovery was apparent, followed by a slow component (see Fig. $4 C$ for normalized comparison of recovery). The slow component was fitted with a single exponential with a time constant of $78.8 \pm 16.1 \mathrm{sec}$ $(n=8)$, similar to $\tau_{\text {slow }}$ at $\leq 7$ DIV (Fig. $\left.4 D\right)$. We could not determine the time constant of the fast component, because higher stimulation rates caused changes in the amplitude of the EPSC, consistent with altered transmitter release and/or receptor desensitization. However, the fast component was fully developed at $0.3 \mathrm{~Hz}$ (data not shown), suggesting a time constant of $\leq 1 \mathrm{sec}$. The biphasic recovery was not limited to neurons at $\geq 13$ DIV. A rapid component of recovery was observed for EPSCs at $\leq 7 \mathrm{DIV}$ that had a lower ifenprodil sensitivity, in the range for EPSCs $\geq 13$ DIV.

The slow component of recovery at both $\leq 7$ and $\geq 13$ DIV is consistent with the presence of NR1/NR2B receptors at these synapses, whereas the reduced ifenprodil sensitivity and fast component of recovery indicate that receptors with a different subunit composition, possibly NR1/NR2A/NR2B triheteromers, are also present. Consistent with this hypothesis, the fast component was larger for EPSCs that were less sensitive to ifenprodil. For EPSCs in which the block by ifenprodil suggested a homogeneous population of NR1/NR2B receptors $\left(\mathrm{I}_{\text {ifen }}<25 \%\right.$ of control), the fast component contributed $12.6 \pm 1.9 \%(n=7)$. For EPSCs that were less ifenprodil-sensitive $\left(\mathrm{I}_{\text {ifen }}>25 \%\right.$ of control), the fast component was $33.3 \pm 3.7 \%(n=16$; Fig. $4 E)$.

\section{Ifenprodil sensitivity of triheteromeric receptors containing NR1, NR2A, and NR2B}

A comparison of the ifenprodil sensitivity of native receptors with recombinant NR1/NR2 diheteromers is straightforward if native receptors consist of either highly sensitive NR1/NR2B receptors or ifenprodil-insensitive NR1/NR2A receptors. However, native receptors can contain both NR2A and NR2B subunits (Sheng et al., 1994). Whether triheteromeric receptors composed of NR1, NR2A, and NR2B are as sensitive to ifenprodil as NR1/NR2B receptors is unknown. To address this question, we transfected HEK293 cells with 1:1, 1:10, and 1:100 ratios of cDNA for NR2A:NR2B along with NR1 and compared the ifenprodil sensitivity with cells transfected with NR1/NR2A and NR1/NR2B. As expected, recombinant NR1/NR2A receptors in our experiments were not blocked by ifenprodil $(100.7 \pm 5.7 \%$ of control; $n=10$; Fig. $5 A, B)$, whereas $\mathrm{NR} 1 / \mathrm{NR} 2 \mathrm{~B}$ receptors were highly sensitive (Figs. $2 C, 5 B$ ). Cells transfected with both NR2A and NR2B showed intermediate sensitivities. $\mathrm{I}_{\text {ifen }}$ was $75 \pm 4.1 \%$ of control $(n=33)$ for a 1:1 ratio of NR2A:NR2B and $76.4 \pm 4.2 \%$ of control $(n=19)$ for a $1: 10$ ratio. The inhibition by ifenprodil for the 1:100 ratio was greater ( $35 \pm 2.7 \%$ of control; $n=15$; Fig. $5 B)$. However, the responses from these cells appeared to fall into two groups (Fig. $5 C, D$ ). In eight cells, $\mathrm{I}_{\text {ifen }}$ was $10 \pm 3.1 \%$ of control, similar to results from NR1/NR2B diheteromers, whereas the remaining seven cells had an intermediate ifenprodil 
A

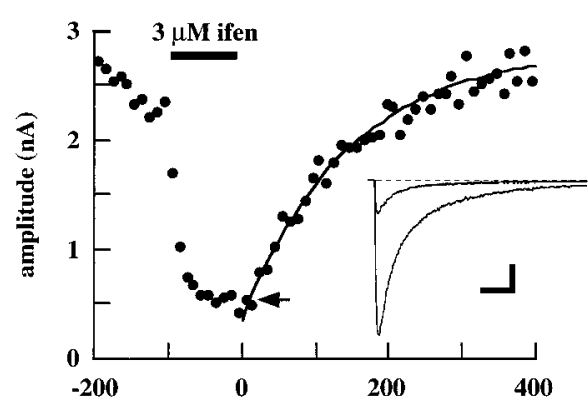

\section{B}

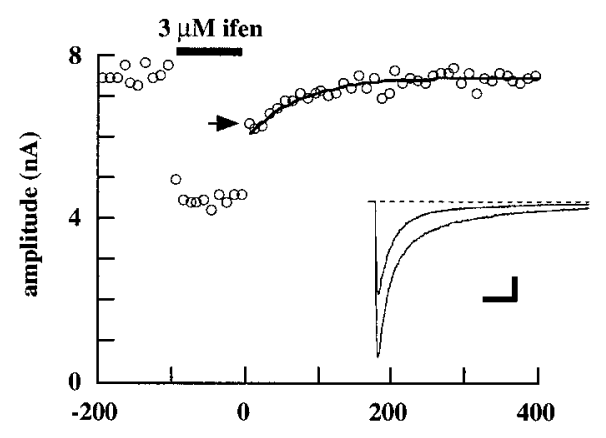

C

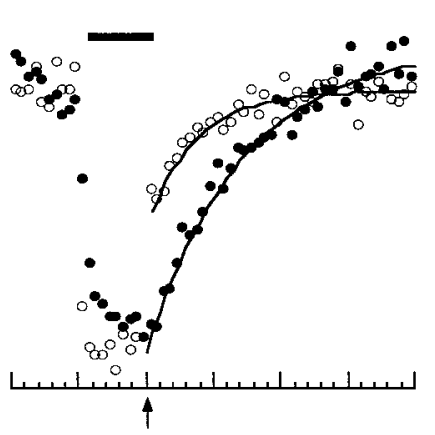

D

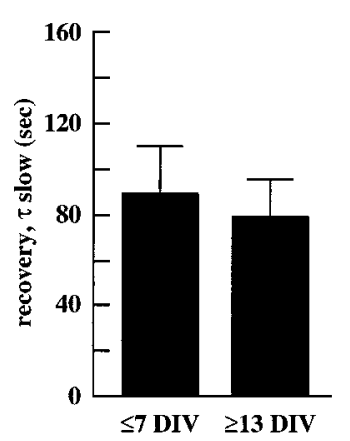

$\mathbf{E}$

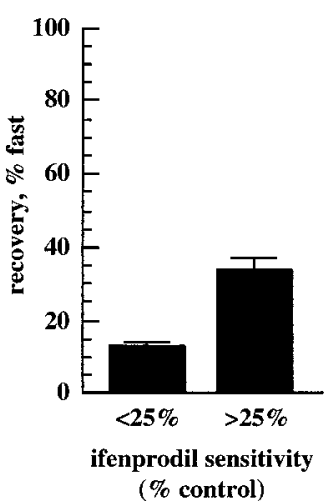

Figure 4. Synaptic NMDA receptor complement can be composed of two distinct types of NMDA receptors. $A$, Plot of peak NMDA EPSC amplitude as a function of recording time from a neuron at 7 DIV. The plot represents the amplitude of the last 10 EPSCs before the $3 \mu \mathrm{M}$ ifenprodil (ifen) application followed by the amplitude of 10 EPSCs in ifenprodil. The solid bar represents the ifenprodil application. The arrowhead points to the first EPSC after ifenprodil removal. $B$, As in $A$, except from a neuron at 15 DIV. $A, B$, insets, EPSCs in control and in $3 \mu \mathrm{M}$ ifenprodil. Calibration: $400 \mathrm{pA}, 1 \mathrm{nA}$, respectively; $100 \mathrm{msec}$ for both. Note that in this example the first EPSC after ifenprodil removal had recovered more than half of the total extent of block in the $10 \mathrm{sec}$ interval between EPSCs (arrowhead). Stimulus frequency is $0.1 \mathrm{~Hz}$, and current amplitudes were measured with a $5 \mathrm{msec}$ window around the peak. Ifenprodil was applied with a flow pipe positioned 50$100 \mu \mathrm{m}$ from the soma. In both cases the recovery from block was fitted with a single exponential starting at the first data point after ifenprodil removal. $C$, Normalized plots from $A$ and $B$ to show the extent of recovery after ifenprodil removal. The arrow indicates the last EPSC in ifenprodil. $D$, Comparison of the slow recovery time constants of EPSCs from $\leq 7 \mathrm{DIV}$ and $\geq 13$ DIV neurons. $E$, EPSCs that were more sensitive to block by

ifenprodil recovered less in the first interval after ifenprodil removal than that EPSCs that were less sensitive to ifenprodil block.

sensitivity ( $48.4 \pm 5.4 \%$ of control). The receptor complement in the highly ifenprodil-sensitive cells most likely represented NR1/ NR2B diheteromers. Because there was 100 times more NR2B cDNA, these cells probably did not receive sufficient NR2Acontaining plasmid to affect the whole-cell current. However, the cells with intermediate ifenprodil sensitivity suggest an additional population of triheteromeric receptors.

For ratios of 1:1 and 1:10, the intermediate ifenprodil sensitivity could result from a mixed population of ifenprodil-insensitive NR1/NR2A and ifenprodil-sensitive NR1/NR2B receptors. In this case, the recovery from block should match NR1/NR2B receptors. We tested this possibility by examining the recovery from block from cells transfected with a 1:1 ratio of NR2A:NR2B (Fig. 6A). The half-recovery times for cells transfected with a 1:1 ratio of NR2A:NR2B was much faster $(0.49 \pm 0.28 \mathrm{sec} ; n=7)$ than NR1/NR2B diheteromers (Fig. 6B). Thus these experiments indicate the presence of triheteromeric NR1/NR2A/ NR2B receptors with an intermediate ifenprodil sensitivity.

\section{DISCUSSION}

The microdot culture system allowed us to compare EPSCs and whole-cell currents from neurons during the development of synaptic load. Our data are consistent with the NMDA receptor complement being composed largely of NR1/NR2B diheteromers before synapse formation. Soon after synapse formation begins, the majority of NMDA receptors are still extrasynaptic and highly ifenprodil-sensitive. However, the synaptic NMDA receptor complement differs in its ifenprodil sensitivity because of the rapid appearance of less ifenprodil-sensitive (possibly triheteromeric) receptors. The addition of less ifenprodil-sensitive receptors as synaptic load is increasing may indicate that NMDA receptors incorporating $\mathrm{NR} 2 \mathrm{~A}$ subunits are localized at synaptic sites soon after synapses become functional.

\section{Comparison with previous data}

Our results rely on the subunit specificity of ifenprodil. Previous results in heterologous expression systems indicate that ifenprodil at the concentrations used in our experiments maximally blocks NR1/NR2B receptors without affecting NR1/NR2A receptors (Williams, 1993). This was confirmed in our experiments with recombinant receptors expressed in HEK293 cells. Whole-cell currents in cultured hippocampal neurons were blocked by ifenprodil as previously demonstrated (Legendre and Westbrook, 1991). Based on their similar degree of block and macroscopic kinetics, we conclude that extrasynaptic receptors at 5-7 DIV are largely composed on NR1/NR2B diheteromers, consistent with the early expression of the NR2B subunit (Monyer et al., 1994; Kew et al., 1998).

Ifenprodil has recently been used to study native NMDA receptor subunit composition as well as developmental changes in NMDA receptor phenotype. In whole-cell recordings of acutely isolated cortical neurons, a developmental shift in ifenprodil sensitivity and a reduction in glycine affinity were coincident with an increase in NR2A expression (Kew et al., 1998). These authors also reported that ifenprodil had a biphasic dose-response curve in neurons from older animals. Decreased glycine affinity is consistent with increased expression of NR2A (Kutsuwada et al., 1992). A two-component mechanism was also responsible for ifenprodil block of EPSCs in CA1 pyramidal neurons in slices from 7- to 28-d-old mice (Kirson and Yaari, 1996). The ratio of high to low ifenprodil-sensitive components decreased in neurons from animals older than $35 \mathrm{~d}$. Plant et al. (1997) found that 
A

Figure 5. High ifenprodil sensitivity is a property of NR1/NR2B receptors. HEK293 cells were transfected with varying ratios of NR2A and NR2B subunit, as well as with NR2A or NR2B alone. $A$, Whole-cell current relaxations in ifenprodil from HEK293 cells transfected with (from the top) NR1/NR2B, NR1/ NR2A/NR2B, NR1/NR2A/10NR2B (overlapping), or NR1/NR2A alone. $B$, Plots of all the data from these experiments. $C$, Two groups of responses from the $1: 100$ NR2A:NR2B transfections. $D$, Distribution of ifenprodil sensitivity from the group transfected with 1:100 NR2A: NR2B. Bars above the currents in $A$ and $C$ are as in Figure $1 C$. Data in $A$ and $C$ were normalized to the start of ifenprodil application (as indicated by the arrowhead).

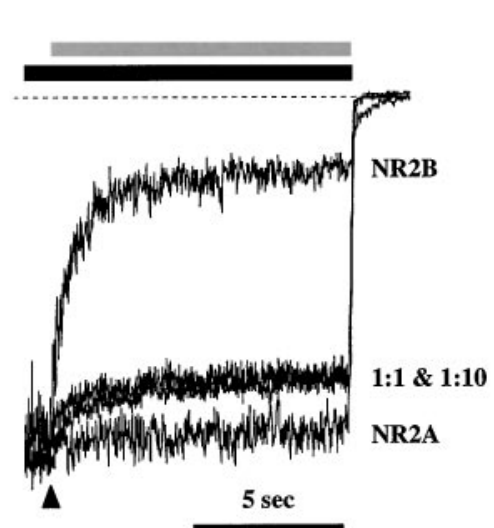

B
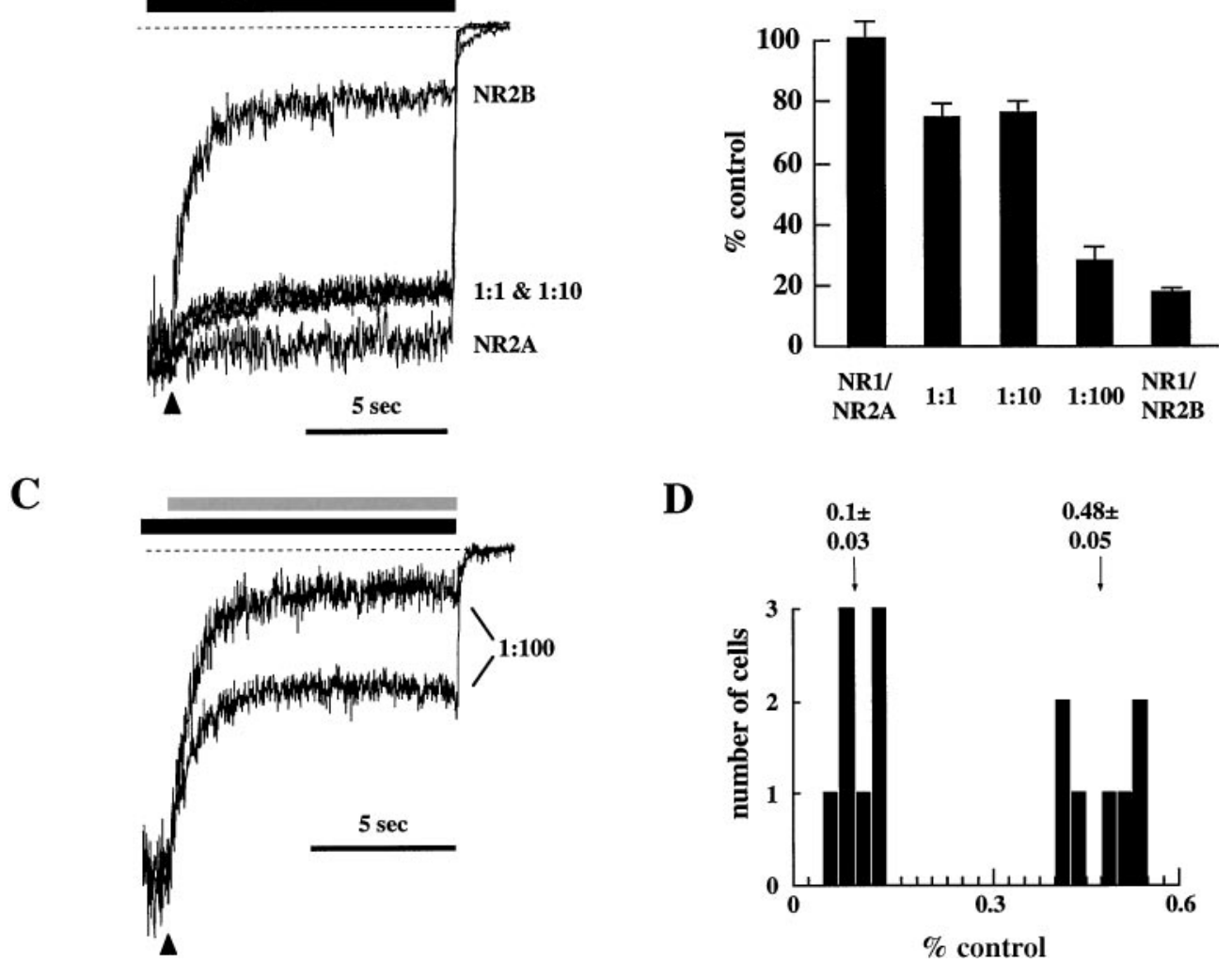

D

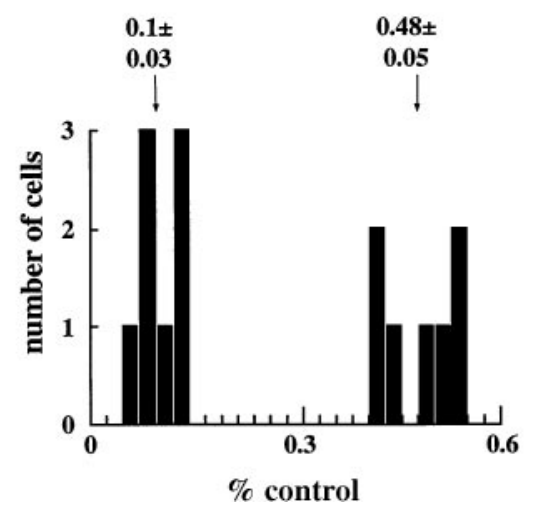

EPSCs in GABAergic forebrain neurons in slice recordings from 14- to 17-d-old rats were highly variable in their sensitivity to ifenprodil ( $3 \mu \mathrm{M}$; range, $48-93 \%$ block). These results are consistent with our results indicating that synapse formation triggers heterogeneity in the synaptic NMDA receptor population.

Using whole-cell currents to inform us about synaptic NMDA receptors initially seemed like a reasonable strategy, because synaptic NMDA receptors outnumber extrasynaptic receptors by 4:1 on neurons at 9-14 DIV (Rosenmund et al., 1995). However, direct measurement of the extrasynaptic/synaptic ratio at 5-7 DIV indicated that the majority of receptors were extrasynaptic. Whole-cell currents at this stage predominantly reflect the properties of extrasynaptic receptors and thus do not provide an accurate sampling of synaptic receptors. The lower ifenprodil sensitivity of synaptic receptors compared with extrasynaptic receptors implies that there is rapid incorporation of pharmacologically distinct NMDA receptors into synaptic sites. Using a different approach, Stocca and Vicini (1998) have come to similar conclusions regarding NMDA receptor-mediated EPSCs in cortical slices. Whether the incorporation of new, presumably triheteromeric receptors occurs at synapses already containing NR1/ NR2B receptors remains to be determined.

\section{Role of NR2B and implications for synapse formation and maturation}

Mice lacking NR2B die soon after birth and have no detectable NMDA receptor component of the EPSP (Kutsuwada et al., 1996). This probably results from an inability to form functional channels rather than a general defect in localization of synaptic receptors, because cultured neurons from these mice have NMDA receptor-mediated EPSCs, with properties that are consistent with expression of NR1/NR2A diheteromers (Tovar et al., 1998).
Proteins that bind to intracellular domains of NMDA receptor subunits have recently been identified (for review, see Gomperts, 1996; Ziff 1997). Many of these proteins have homology to signal transduction molecules, whereas others may anchor these transduction molecules to the PSD. Mice lacking the NR2A subunit have attenuated long-term potentiation (LTP) and are deficient in some learning paradigms but are otherwise viable (Sakimura et al., 1995). The deficiency in LTP in mice lacking NR2A could result from the lack of an anchoring or association site for molecules important in LTP. The NR2A and NR2B subunits both contain a PDZ-binding sequence required for attachment to that class of "scaffolding" proteins (Kornau et al., 1995). However, in hippocampal neurons, the commonly expressed PDZ-containing protein, PSD-95, must not be initially responsible for clustering of NMDA receptors at synapses, because immunocytochemical colocalization of PSD-95 with NMDA receptor subunits does not occur until 21 DIV (Rao et al., 1998). Our results indicate that synapses containing AMPA and NMDA receptor components have formed long before that time.

In contrast to our work, Rao and Craig (1998) used immunocytochemistry to demonstrate that NR2A- and NR2B-containing clusters become localized at sites opposite clusters of the presynaptic marker synaptophysin after 14 DIV. They inferred from this that synaptic localization of NMDA receptors does not occur until that time and after localization of AMPA receptors (as inferred from clusters of the AMPA receptor subunit GluR1). However, our results indicate that functional synapses form after $5 \mathrm{~d}$ in culture, that NMDA receptors are present at these nascent synapses, and that NR2B subunits initially predominate at these sites. The differences between the physiological and immunocytochemical results may arise from an inability to detect with 
A

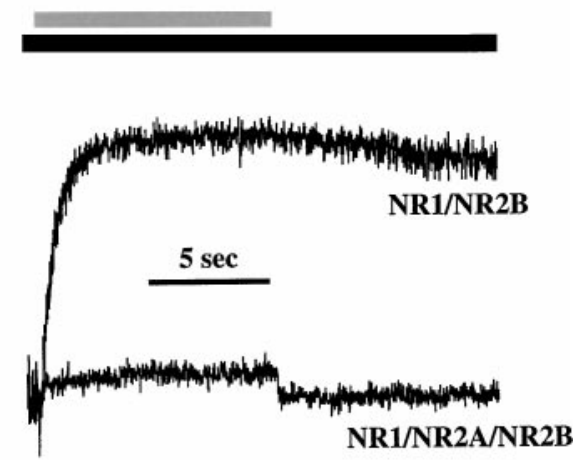

B

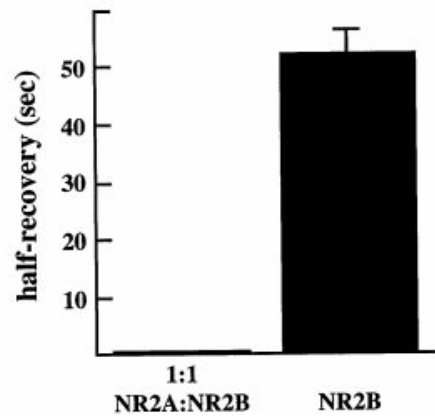

Figure 6. HEK293 cells transfected with NR1, NR2A, and NR2B recover quickly from ifenprodil block. $A$, Protocol for measuring the recovery from block from triply transfected cells (with a 1:1 ratio of NR2A: NR2B) and the recovery from block of an NR1/NR2B-transfected cell for comparison. Data for block recovery are shown in $B$. Recovery data for NR1/NR2B cells are reiterated from Figure $3 C$ and collected using the method illustrated in Figure $3 B$. This method could not be used for triply transfected cells, because often the recovery was completed in the interval between the removal of ifenprodil and the first application of NMDA alone. Instead, recovery was measured by returning to the NMDA solution lacking ifenprodil. An example using this method of measuring recovery from block from NR1/NR2B receptors is shown for comparison. Bars above the current are as in Figure $1 C$.

immunohistochemical methods small numbers of receptors at nascent synapses.

\section{Nascent and mature synapses}

We present the following hypothesis for formation and maturation of the synaptic NMDA receptor complement in our system. Nascent synaptic NMDA receptors are NR1/NR2B diheteromers. This is likely because before synapse formation the properties of NMDA receptors are similar to those of recombinant NR1/NR2B receptors. Once a synapse has formed, activity at that synapse results in incorporation of another NMDA receptor type, NR1/NR2A/NR2B triheteromers, which are specifically targeted to synapses. A corollary of this hypothesis, not tested directly by our experiments, is that synapses initially form promiscuously. Only after they have formed does input-dependent alteration of the NMDA receptor phenotype at that synapse occur. Our model does not consider the possible role for the newly discovered NR3 subunit, which is developmentally expressed (Das et al., 1998).

Our model implies that an input-dependent event occurs such that the synaptic receptor complement changes at functional synapses. This is directly analogous to the developing neuromuscular junction (NMJ), where acetylcholine receptor channel ki- netics (Cull-Candy et al., 1982; Brenner and Sakmann, 1983) differ between extrasynaptic and synaptic populations of channels. Changes in the kinetic properties of ACh channels are thought to result from factors provided by the presynaptic nerve terminal (Brenner and Sakmann, 1983). For a central excitatory synapse, the nature of the presynaptic signal may be activity at that synapse or a factor from the presynaptic terminal analogous to acetylcholine receptor-inducing activity (ARIA; Fischbach and Rosen 1997) at the NMJ. The maturation of EPSC kinetics and their pharmacological properties at cultured CA1 hippocampal neurons seem to be dependent on tetanus toxin-sensitive exocytosis (Lindlbauer et al., 1998) (also see Gottmann et al., 1997), consistent with this idea. Recently a member of the ARIA family, neuregulin- $\beta$, has been implicated in changes in NMDA receptor subunit expression that occur in cerebellar granule cells (Ozaki et al., 1997). In support of the idea that NMDA receptor activity results in changes in the receptor complement at active synapses, hippocampal neurons cultured in AP5 show a heightened sensitivity to ifenprodil, as if NMDA receptors at all synaptic sites were pure NR1/NR2B diheteromers (Chavis and Westbrook, 1998).

Our evidence indicates that nascent synapses are homogenous with respect to their NMDA receptor complement. A model of cortical development holds that changes in NMDA receptor subunit composition are important in governing the period during which synaptic rearrangements can occur (Sheetz and Constantine-Paton, 1994). An elaboration of this model is that sites with more than one type of NMDA receptor are the very sites that are capable of being modified, and they are marked by the presence of NR2A-containing receptors. This is supported by the apparent speed with which NR2A-containing receptors appeared at synapses in this study (also see Stocca and Vicini, 1998). Blockade of NMDA receptors in vivo prevents the formation of topographic maps (Cline and Constantine-Paton, 1987; Kleinschmidt et al., 1987) and also prevents the change from high to low NMDA EPSC ifenprodil sensitivity (Chavis and Westbrook, 1998). If NMDA channel gating acts on the same mechanisms in these systems, neural activity at synapses containing diheteromeric and triheteromeric NMDA receptors may be required for the formation of correlation-based topographic maps. Thus NR1/ NR2B-only synapses may mark new synapses available for further elaboration, and synapses with diheteromeric and triheteromeric receptors may mark synapses that are subject to correlation-based refinement. The limit of correlation-based synaptic refinement (i.e., the critical period duration) may occur when synapses contain only triheteromeric receptors.

\section{REFERENCES}

Bekkers JM, Stevens CF (1991) Excitatory and inhibitory autaptic currents in isolated hippocampal neurons maintained in cell culture. Proc Natl Acad Sci USA 88:7834-7838.

Brenner HR, Sakmann B (1983) Neurotrophic control of channel properties at neuromuscular junction synapses of rat muscle. J Physiol (Lond) 337:159-171.

Carmingnoto G, Vicini S (1992) Activity-dependent decreases in NMDA receptor responses during development of the visual cortex. Science 258:1007-1011.

Chavis P, Westbrook GL (1998) "Pure" NR2B-containing synapses have a high release probability in cultured hippocampal neurons. Soc Neurosci Abstr 24:845.

Chen C, Okayama H (1987) High-efficiency transformation of mammalian cells by plasmid DNA. Mol Cell Biol 7:2745-2752.

Cik M, Chazzot PL, Stephenson FA (1993) Optimal expression of cloned NMDAR1/NMDAR2A heteromeric glutamate receptors: a biochemical characterization. Biochem J 296:877-883. 
Cline HT, Constantine-Paton M (1987) NMDA receptor antagonists disrupt the retinotectal topographic map. Neuron 3:413-426.

Cull-Candy SG, Miledi R, Uchitel OD (1982) Properties of junctional and extrajunctional acetylcholine-receptor channels in organ cultured human muscle fibers. J Physiol (Lond) 333:251-267.

Das S, Sasaki YF, Rothe T, Premkumar LS, Takasu M, Crandall JE, Dikes P, Conner DA, Rayudu PV, Cheung W, Chen HS, Lipton SA, Nakanishi N (1998) Increased NMDA current and spine density in mice lacking the NMDA receptor subunit NR3A. Nature 393:377-381.

Fischbach GD, Rosen KM (1997) ARIA: a neuromuscular junction neuregulin. Annu Rev Neurosci 20:429-458.

Forrest D, Yuzaki M, Soares HD, Ng L, Luk DC, Sheng M, Stewart CL, Morgan JI, Conner JA, Curran T (1994) Targeted disruption of NMDA receptor 1 gene abolishes NMDA response and results in neonatal death. Neuron 13:325-338.

Gomperts SN (1996) Clustering membrane proteins: it's all coming together with the PSD-95/SAP90 protein family. Cell 84:659-662.

Gottmann K, Mehrle A, Gisselmann G, Hatt H (1997) Presynaptic control of subunit composition of NMDA receptors mediating synaptic plasticity. J Neurosci 17:2766-2774.

Hestrin S (1992) Developmental regulation of NMDA receptormediated synaptic currents at a central synapse. Nature 357:686-689.

Huettner JE, Bean BP (1988) Block of $N$-methyl-D-aspartate-activated current by the anticonvulsant MK-801: selective binding to open channels. Proc Natl Acad Sci USA 85:1307-1311.

Kew JN, Richards JG, Mutel V, Kemp JA (1998) Developmental changes in NMDA receptor glycine affinity and ifenprodil sensitivity reveal three distinct populations of NMDA receptors in individual rat cortical neurons. J Neurosci 18:1935-1943.

Kirson ED, Yaari Y (1996) Synaptic NMDA receptors in developing mouse hippocampal neurones: functional properties and sensitivity to ifenprodil. J Physiol (Lond) 497:437-455.

Kleinschmidt A, Bear MF, Singer W (1987) Blockade of NMDA receptors disrupts experience-dependent plasticity of kitten striate cortex. Science 238:355-358.

Kohr G, Seeburg PH (1996) Subtype-specific regulation of recombinant NMDA receptor-channels by protein tyrosine kinases of the src family. J Physiol (Lond) 492:445-452.

Kornau H-C, Schenker LT, Kennedy MB, Seeburg PH (1995) Domain interactions between NMDA receptor subunits and the postsynaptic density protein PSD-95. Science 269:1737-1740.

Krupp JJ, Vissel B, Heinemann SJ, Westbrook GL (1998) N-terminal domains in the NR2 subunit control desensitization of NMDA receptors. Neuron 20:317-327.

Kutsuwada T, Kashiwabuchi N, Mori H, Sakimura K, Kushiya E, Araki K, Meguro H, Masaki H, Kumanishi T, Arakawa M, Mishina M (1992) Molecular diversity of the NMDA receptor channel. Nature 358:36-41.

Kutsuwada T, Sakimura K, Manabe T, Takayama C, Katakura N, Kushiya E, Natsume R, Watanabe M, Inoue Y, Yagi T, Aizawa S, Arakawa M, Takahashi T, Nakamura Y, Mori H, Mishina M (1996) Impairment of suckling response, trigeminal neuronal pattern formation, and hippocampal LTD in NMDA receptor $\epsilon 2$ subunit mutant mice. Neuron 16:333-344.

Laurie DJ, Putzke J, Zieglgansberger W, Seeburg PH (1995) The distribution of splice variants of the NMDAR1 subunit mRNA in the adult rat brain. Mol Brain Res 32:94-108.

Legendre P, Westbrook GL (1991) Ifenprodil blocks $N$-methyl-Daspartate receptors by a two-component mechanism. Mol Pharmacol 40:289-298.

Legendre P, Rosenmund C, Westbrook GL (1993) Inactivation of NMDA channels in cultured hippocampal neurons by intracellular calcium. J Neurosci 13:674-684.

Li JH, Wang YH, Wolfe BB, Krueger KE, Corsi L, Stocca G, Vicini S (1998) Developmental changes in localization of NMDA receptor sub- units in primary cultures of cortical neurons. Eur J Neurosci 10:1704-1715.

Lindlbauer R, Mohrmann R, Hatt H, Gottmann K (1998) Regulation of kinetic and pharmacological properties of synaptic NMDA receptors depends on presynaptic exocytosis in rat hippocampal neurons. J Physiol (Lond) 508:495-502.

McBain CJ, Mayer ML (1994) NMDA receptor structure and function. Physiol Rev 74:723-760.

McDonald JW, Johnston MV (1990) Physiological and pathophysiological roles and excitatory amino acids during central nervous system development. Brain Res Rev 15:41-70.

Monyer H, Burnashev N, Laurie DJ, Sakmann B, Seeburg PH (1994) Developmental and regional expression in the rat brain and functional properties of four NMDA receptors. Neuron 12:529-540.

Ozaki M, Sasner M, Yano R, Lu HS, Buonanno A (1997) Neuregulin- $\beta$ induces expression of an NMDA-receptor subunit. Nature 390:691-694.

Plant T, Schirra C, Garaschuk O, Rossier J, Konnerth A (1997) Molecular determinants of NMDA receptor function in GABAergic neurones of rat forebrain. J Physiol (Lond) 499:47-63.

Rao A, Craig AM (1998) Activity regulates the synaptic localization of the NMDA receptor in hippocampal neurons. Neuron 19:801-812.

Rao A, Kim E, Sheng M, Craig AM (1998) Heterogeneity in the molecular composition of excitatory postsynaptic sites during development of hippocampal neurons in culture. J Neurosci 18:1217-1229.

Rosenmund C, Clements JD, Westbrook GL (1993) Nonuniform probability of glutamate release at a hippocampal synapse. Science 262:754-757.

Rosenmund C, Feltz A, Westbrook GL (1995) Synaptic NMDA receptor channels have a low open probability. J Neurosci 15:2788-2795.

Sakimura K, Kutsuwada T, Ito I, Manabe T, Takayama C, Kushiya E, Yagi T, Aizawa S, Inoue Y, Sugiyama H, Mishina M (1995) Reduced hippocampal LTP and spatial learning in mice lacking NMDA receptor $\epsilon 1$ subunit. Nature 373:151-155.

Sheetz AJ, Constantine-Paton M (1994) Modulation of NMDA receptor function: implications for vertebrate neural development. FASEB J $8: 745-752$.

Sheng M, Wyszynski M (1997) Ion channel targeting in neurons. Bioessays 19:847-853.

Sheng M, Cummings J, Roldan LA, Jan YN, Jan LY (1994) Changing subunit composition of heteromeric NMDA receptors during development in rat cortex. Nature 368:144-147.

Sprengel R, Suchanek B, Amico C, Brusa R, Burnashev N, Rozov A, Hvalby O, Jensen V, Paulsen O, Andersen P, Kim JJ, Thompson RF, Sun W, Webster LC, Grant SG, Eilers J, Konnerth A, Li J, McNamara JO, Seeburg PH (1998) Importance of the intracellular domain of NR2 subunits for NMDA receptor function in vivo. Cell 92:279-289.

Stocca G, Vicini S (1998) Increased contribution of NR2A subunit to synaptic NMDA receptors in developing rat cortical neurons. J Physiol (Lond) 507:13-24.

Tovar KR, Miller AJ, Westbrook GL (1998) The $\epsilon 2$ NMDA receptor subunit is not required for synaptic clustering of NMDA receptors. Soc Neurosci Abstr 24:90.

Williams K (1993) Ifenprodil discriminates subtypes of the $N$-methyl-Daspartate receptor: selectivity and mechanisms at recombinant heteromeric receptors. Mol Pharmacol 44:851-859.

Wyszynski M, Lin J, Rao A, Nigh E, Beggs AH, Craig AM, Sheng M (1997) Competitive binding of $\alpha$-actinin and calmodulin to the NMDA receptor. Nature 385:439-442.

Ziff EB (1997) Enlightening the postsynaptic density. Neuron 19:1163-1174.

Zhong J, Russell SL, Pritchett DB, Molinoff PB, Williams K (1994) Expression of mRNAs encoding subunits of the $N$-methyl-D-aspartate receptor in cultured cortical neurons. Mol Pharmacol 45:846-853. 